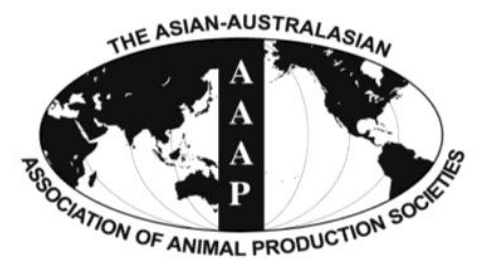

\title{
Effects of Catechins and Wheat Bran on the Beef Color in the Late Fattening Period of Hanwoo Steers
}

\author{
Do Hyung Kim ${ }^{1}$, Young Kyoon Oh, Sun Sik Jang, Eung Gi Kwon, Yong Joo Seol, Ji Un Ok, \\ Keun Kyu Park ${ }^{2}$, Sung Sill Lee ${ }^{3}$ and Kyoung Hoon Kim* \\ National Institute of Animal Science, RDA, Suwon 441-706, Korea
}

\begin{abstract}
This study was conducted to evaluate the effects of dietary supplementation of catechins and wheat bran on growth performance, carcass characteristics and meat color using forty-eight Hanwoo steers. Each steer was randomly assigned to one of four treatments. Treatments were as follows: control, catechins, wheat bran, and catechins+wheat bran (CW). At the end of the feeding trial, blood samples were collected for analysis of hemoglobin and iron concentration, and then steers were slaughtered at a commercial abattoir. Catechins, wheat bran, and CW had no effect on growth performance and carcass characteristics. Percentage of myoglobin in M. longissimus dorsi was not affected by treatments. Percentage of oxymyoglobin was increased ( $<<0.05)$ by $\mathrm{CW}$ and maintained at the highest level $(\mathrm{p}<0.05)$ for $\mathrm{CW}$ during meat display time up to $24 \mathrm{~h}$. Percentage of metmyoglobin was the lowest $(\mathrm{p}<0.05)$ for $\mathrm{CW}$ between 5 and $24 \mathrm{~h}$ during display time. Although blood iron concentration was not affected by treatments, total concentration of muscle iron was the lowest $(\mathrm{p}<0.05)$ for $\mathrm{CW}$ compared with that of other treatments. Therefore, the results of the present study suggest that $\mathrm{CW}$ may provide good protection against oxidation of myoglobin, and might be an effective dietary supplement for improving meat color in the late fattening period of Hanwoo steers. (Key Words: Catechins, Wheat Bran, Meat Color, Hanwoo Steer)
\end{abstract}

\section{INTRODUCTION}

Meat color is an important factor in determining meat quality grade and a good indicator of the degree of freshness of meat. In most countries, consumers significantly consider meat color when they purchase meat and prefer a bright red color (Carpenter et al., 2001). Decisions when purchasing meat are influenced by meat color more than any other meat quality factor because consumers consider discoloration an indicator of spoilage. In addition, meat color is judged by perceived eating quality and desirability (Cassens et al., 1988).

Meat color is influenced by heritability and environment as well as nutritional factors. Regarding nutritional factors, Bray et al. (1959) reported that iron supplementation increased pigment concentration in muscular tissues, and

\footnotetext{
* Corresponding Author: Kyoung Hoon Kim. Tel: +82-31-2901698, Fax: +82-31-290-1660, E-mail: kh665@korea.kr

${ }^{1}$ Department of Animal and Food Sciences, University of Kentucky, USA.

${ }^{2}$ Department of Animal Science, KonKuk University, Korea.

${ }^{3}$ Division of Applied Life Science (BK21 Program), Graduate School of Gyeongsang National University, Korea.

Submitted Dec. 9, 2011; Accepted Feb. 6, 2012; Revised Mar. 4, 2012
}

this resulted in the production of darker colored meat. Zembayashi et al. (1999) confirmed that there was a correlation $\left(y=64.37-19.35 x+3.54 x^{2}, r^{2}=0.79\right)$ between iron concentration and $\mathrm{L}^{*}$ value (lightness), and suggested that beef color could be improved by a reduction in iron concentration of muscle.

A few studies have been conducted to estimate the effects of iron concentration on beef color. Phytate, catechins and tannins have resulted in reduced absorption of iron (Disler et al., 1975; Monsen, 1988; Goto et al., 1996). There are reports that beef color tends to improve with supplementation of green tea, bran and soy hulls. Phenolic compounds have demonstrated antioxidant capacity resulting in preservation of meat color. Catechins, a natural phenol antioxidant and plant secondary metabolite, are abundant in green tea. Wheat bran, a by-product feedstuff, offers an alternative to cereal grains by providing the ruminant with energy primarily from degradable fiber. Wheat bran can also serve as an alternative natural antioxidant as demonstrated by Onyeneho and Hettiarachchy (1992). Although the antioxidative properties of dietary supplementation with wheat bran have already been studied in beef cattle, few data are available on their effect on meat quality in beef cattle, with no references to 
meat color in Hanwoo steers. We hypothesized that wheat bran, as a source of phosphate, could reduce the absorption of iron in the digestive tract and consequently the iron concentration of muscle; and wheat bran and catechins, being phenolic antioxidants, may result in improvement of meat color and shelf life. Therefore, this study was conducted to evaluate effects of dietary supplementation of wheat bran and catechins on meat color in Hanwoo steers.

\section{MATERIALS AND METHODS}

\section{Animals, diets, and management}

A feeding trial was conducted for 10 months at the National Agricultural Cooperative Federation Farm located in Anseong, South Korea. Forty-eight Hanwoo steers were used in a completely randomized design to determine the effects of feedstuffs on meat color in the late fattening period. The steers were allotted to one of 4 treatment groups with six steers per pen and two pens per treatment. Treatments were as follows: control (Basal diet), catechins, wheat bran, and catechins+wheat bran $(\mathrm{CW})$. Average BW
( \pm SD) of the steers at the beginning of the trial was $486 \pm 30$ $\mathrm{kg}$. The experiment was carried out from 20 months to 30 months of age. All groups received concentrate feed $\mathrm{ad}$ libitum and $1 \mathrm{~kg} / \mathrm{animal} / \mathrm{d}$ rice straw throughout the feeding trial until slaughter. Ingredient composition and chemical analysis of the concentrate diets are shown in Table 1 . The DM content of the rice straw was $88.4 \%$, and the CP, NDF, and ADF contents were 4.4, 49.2 and $31.9 \%$ (DM basis), respectively.

Steers were fed the experimental diets twice daily at 0800 and $1700 \mathrm{~h}$, and had free access to mineral blocks. Each treatment diet was fed to steers via an individual gate feeding system. Water was freely accessible through the automatic waterers. At the end of the feeding trial, all animals were slaughtered at a commercial abattoir (National Agricultural Cooperative Federation, Seoul, South Korea).

\section{Sampling, measurements, and chemical analysis}

Throughout the feeding trial, daily feed intake was calculated as the difference between the daily feed supply and refusals, and weight gain was calculated as the

Table 1. Ingredient composition and chemical analysis of the experimental diets ${ }^{\mathrm{a}}$

\begin{tabular}{|c|c|c|c|c|}
\hline Items & Control & Catechins & Wheat bran & $\mathrm{CW}$ \\
\hline \multicolumn{5}{|l|}{ Ingredients (As-fed basis, \%) } \\
\hline Corn flakes & 49.94 & 49.44 & 42.24 & 41.74 \\
\hline Corn gluten feed & 15.29 & 15.29 & 10.07 & 10.07 \\
\hline Wheat bran & - & - & 16.28 & 16.28 \\
\hline Beet pulp & 24.44 & 24.44 & 21.12 & 21.12 \\
\hline Molasses & 4.08 & 4.08 & 4.04 & 4.04 \\
\hline Vitamin-mineral additive $\mathrm{e}^{\mathrm{b}}$ & 0.33 & 0.33 & 0.32 & 0.32 \\
\hline Limestone & 0.55 & 0.55 & 0.41 & 0.41 \\
\hline Salt & 0.51 & 0.51 & 0.51 & 0.51 \\
\hline Yeast culture & 2.11 & 2.11 & 2.11 & 2.11 \\
\hline Calcium phosphate & 0.36 & 0.36 & 0.51 & 0.51 \\
\hline Sodium bicarbonate & 0.51 & 0.51 & 0.51 & 0.51 \\
\hline Ammonium chloride & 0.26 & 0.26 & 0.26 & 0.26 \\
\hline Glycerol & 1.51 & 1.51 & 1.51 & 1.51 \\
\hline Lasalocid & 0.11 & 0.11 & 0.11 & 0.11 \\
\hline Catechin & - & 0.50 & - & 0.50 \\
\hline Total & 100.00 & 100.00 & 100.00 & 100.00 \\
\hline \multicolumn{5}{|l|}{ Chemical analysis } \\
\hline Dry matter $(\%)$ & 85.62 & 85.45 & 85.79 & 85.77 \\
\hline Crude protein $(\%$ of DM) & 14.77 & 14.25 & 14.26 & 14.28 \\
\hline Neutral detergent fiber ( $\%$ of DM) & 23.72 & 25.85 & 29.60 & 27.90 \\
\hline Acid detergent fiber ( $\%$ of DM) & 5.32 & 6.13 & 6.13 & 4.71 \\
\hline $\mathrm{Ca}(\%$ of $\mathrm{DM})$ & 1.30 & 1.33 & 1.11 & 1.98 \\
\hline $\mathrm{P}(\%$ of $\mathrm{DM})$ & 0.61 & 0.46 & 0.57 & 0.90 \\
\hline
\end{tabular}

${ }^{\mathrm{a}}$ Steers had free access to mineral blocks (Rincal block, Daehan New Pham, Seoul, Korea; provided following nutrients per kg: I, $150 \mathrm{mg}$; Mn, $200 \mathrm{mg}$;

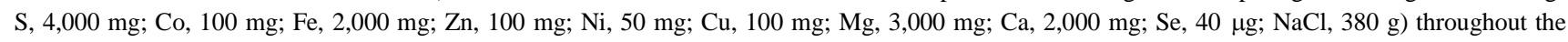
experiment.

${ }^{\mathrm{b}}$ Provided following nutrients per kg of additive (Grobic-DC, Bayer HealthCare, Leverkusen, Germany): Vit. A, 2,650,000 IU; Vit. $\mathrm{D}_{3}$, 530,000 IU; Vit. E, 1,050 IU; Niacin, 10,000 mg; Mn, 4,400 mg; Zn, 4,400 mg; Fe, 13,200 mg; Cu, 2,200 mg; I, 440 mg; Co, 440 mg. 
difference between initial and final body weights.

Experimental diets were dried in a forced-air oven (at $60^{\circ} \mathrm{C}, 48 \mathrm{~h}$ ), ground through a $2-\mathrm{mm}$ screen in a Wiley mill (Model 4; Thomas scientific, Swedesboro, NJ, USA) and analyzed for moisture, $\mathrm{CP}, \mathrm{EE}$, and ash according to the procedure of AOAC (1990). The concentration of NDF corrected for residual ash was determined with heat-stable amylase and sodium sulphate according to the method of Van Soest et al. (1991), while the concentration of ADF corrected for residual ash was determined according to the procedure of AOAC (1990).

Jugular blood samples were collected at the end of the experiment before feeding. Blood samples were collected into 10-ml vacuum tubes (BD Vacutainer, Becton \& Dickinson, NJ, USA) with $\mathrm{K}_{3}$ EDTA or without any anticoagulant, for analysis of hemoglobin and iron concentrations, respectively. Samples for iron analysis were centrifuged (Hicen21, Herolab, Wiesloch, Germany) at $3,000 \times \mathrm{g}$ for $10 \mathrm{~min}$ at $4^{\circ} \mathrm{C}$ to collect serum and stored at $-80^{\circ} \mathrm{C}$ until further analysis. Iron concentrations in the serum samples were analyzed using an automatic blood analyzer (Express Plus, Ciba-Corning, CA, USA). Whole blood samples treated with $\mathrm{K}_{3}$ EDTA were used for analysis of hemoglobin using a portable hemoglobin analyzer (HemoCue Hb 201, HemoCue AB, Angelholm, Sweden).

At the end of feeding trial all steers were slaughtered after a $24 \mathrm{~h}$ fasting period. They were stunned, exsanguinated, and immediately eviscerated. Carcasses were chilled at between 0 to $2^{\circ} \mathrm{C}$ for $24 \mathrm{~h}$. Carcasses were then graded for quality and yield factors from the longissmus muscle taken at 13th rib. Quality and yield grading was performed by trained personnel of the Animal Products Grading Service in Seoul, South Korea. Carcass weight, carcass yield, back-fat thickness and size of loineye area were assessed. Yield grade was classified with a scale of A, B, or C, where A is high yield and $\mathrm{C}$ is low yield. Quality grade was scored on a scale of $1^{++}, 1^{+}, 1,2$, and 3 , which was mainly determined by marbling score but also by meat color, fat color and maturity. Marbling score was evaluated and scored on a scale of 1 to 9 , where 9 is very abundant and 1 is trace amounts. Fat color was scored on a scale of 1 to 7 , where 1 is creamy white and 7 is yellowish. Panel meat color was scored on a scale of 1 to 7 , where 1 is bright red and 7 is dark red. Texture was scored on a scale of 1 to 3 , where 1 is soft and 3 is firm. Maturity was scored on a scale of 1 to 9 , where 1 is young and 9 is old.

Meat pigment in the longissmus muscle samples was analyzed as described by Fleming et al. (1960) and determined by UV spectrophotometer (Uvikon 923, Kontron, Milan, Italy). Total iron concentration was determined in the longissmus muscle samples using the procedure of Rhee and Ziprin (1987).

\section{Statistical analysis}

Data obtained from the experiment were subjected to statistical analysis using the GLM procedure of SAS (SAS Inst. Inc., Cary, NC, USA) according to the model $\mathrm{Y}_{\mathrm{ij}}=$ $\mu+A_{i}+T_{j}+e_{i j}$, where $Y_{i j}, \mu, A_{i}, T_{j}$, and $e_{i j}$ are the response, overall mean, mean effect of animal, mean effect of treatment, and random residual error, respectively. Duncan's multiple range test was used to interpret any significant differences among the mean values of the treatments. Effects were declared significant at $\mathrm{p}<0.05$.

\section{RESULTS AND DISCUSSION}

Table 2 shows that initial and final BWs, BW gain and ADG were not significantly different among treatments. Wheat bran had approximately $71 \%$ of the metabolizable energy content of corn (NRC, 2000). Compared with control, wheat bran did not affect growth performance of steers. Improving weight gain of cattle fed moderately high protein diets may require the use of energy supplements. However, the most commonly used energy supplements, cereal grains, can decrease forage intake and digestibility. Wheat bran offers an alternative to cereal grains by

Table 2. Effects of experimental diets on growth performance and feed intake in Hanwoo steers

\begin{tabular}{lccccc}
\hline \multirow{2}{*}{ Items $^{1}$} & \multicolumn{2}{c}{ Experimental supplements } & \multirow{2}{*}{ SEM $^{2}$} \\
\cline { 2 - 5 } & Control & Catechins & Wheat bran & CW & 12 \\
Number of steers & 12 & 12 & 12 & 20.4 & 1.18 \\
Initial age (months) & 19.8 & 20.0 & 20.6 & 30.6 & 1.22 \\
Final age (months) & 30.0 & 30.3 & 30.9 & 485.8 & 7.36 \\
Initial BW (kg) & 484.3 & 487.7 & 486.6 & 711.5 & 28.37 \\
Final BW (kg) & 720.2 & 719.8 & 702.1 & 224.2 & 26.97 \\
BW gain (kg) & 235.8 & 232.1 & 213.4 & 0.66 & 0.08 \\
ADG (kg/d) & 0.70 & 0.68 & 0.63 & & \\
DMI (kg/d) & & & & 7.79 & 0.07 \\
Concentration & 7.77 & 7.67 & 0.73 & 0.01 \\
Rice straw & 0.72 & 0.72 & 0.73 & & 0.07 \\
\hline
\end{tabular}

${ }^{1} \mathrm{ADG}=$ Average dairy gain; $\mathrm{DMI}=$ Dry matter intake ${ }^{2} \mathrm{SEM}=$ Standard error of the mean. 
Table 3. Effect of experimental diets on carcass characteristics in Hanwoo steers

\begin{tabular}{|c|c|c|c|c|c|}
\hline \multirow{2}{*}{ Items $^{1}$} & \multicolumn{4}{|c|}{ Experimental supplements } & \multirow{2}{*}{$\mathrm{SEM}^{2}$} \\
\hline & Control & Catechins & Wheat bran & $\mathrm{CW}$ & \\
\hline Number of steers* & 12 & 12 & 10 & 10 & \\
\hline Carcass weight (kg) & 419.00 & 416.58 & 406.90 & 413.20 & 4.79 \\
\hline Loin-eye area $\left(\mathrm{cm}^{2}\right)$ & 84.67 & 86.25 & 91.90 & 91.10 & 1.39 \\
\hline Back fat tickness (mm) & $17.17^{\mathrm{a}}$ & $15.83^{\mathrm{a}}$ & $12.20^{\mathrm{b}}$ & $16.40^{\mathrm{a}}$ & 0.68 \\
\hline Dressing percentage $(\%)$ & $61.63^{\mathrm{b}}$ & $62.73^{\mathrm{b}}$ & $65.97^{\mathrm{a}}$ & $63.08^{\mathrm{b}}$ & 0.49 \\
\hline Yield grade (A:B:C, head) & $1: 5: 6$ & $0: 8: 4$ & $3: 6: 1$ & $0: 6: 4$ & \\
\hline Marbling score & 7.08 & 6.42 & 7.20 & 6.10 & 0.26 \\
\hline Meat color & 4.83 & 4.58 & 4.50 & 4.90 & 0.07 \\
\hline Fat color & 2.92 & 3.00 & 3.00 & 3.00 & 0.02 \\
\hline Texture & 1.08 & 1.00 & 1.10 & 1.10 & 0.04 \\
\hline Maturity & $2.42^{\mathrm{a}}$ & $2.33^{\mathrm{ab}}$ & $2.00^{\mathrm{b}}$ & $2.05^{\mathrm{b}}$ & 0.07 \\
\hline Quality grade $\left(1^{++}: 1^{+}: 1: 2: 3\right.$, head $)$ & $6: 5: 1: 0: 0$ & $4: 5: 2: 1: 0$ & $5: 4: 0: 1: 0$ & $1: 8: 0: 1: 0$ & \\
\hline
\end{tabular}

${ }^{1}$ Area was measured from longissmus muscle taken at 13th rib and back fat thickness was also measured at 13th rib; Carcass yield grades from $\mathrm{C}$ (low yield) to A (high yield). Grading ranges are 1 to 9 for marbling score with higher numbers for better quality $(1=$ traces, $9=$ abundant $)$; meat color $(1=$ bright red, $7=$ dark red); fat color $(1=$ creamy white, $7=$ yellowish $)$; texture $(1=$ soft, $3=$ firm $)$; maturity $(1=$ young, $9=$ old $)$; quality grades from 3 (low quality) to $1^{++}$(very high quality).

${ }^{2} \mathrm{SEM}=$ Standard error of the mean. * Each two observed date of wheat bran and CW were lost.

${ }^{a, b}$ Means with different superscripts within the same row are significantly different $(\mathrm{p}<0.05)$.

providing the ruminant with energy, primarily in the form of degradable fiber (Martin and Hibberd, 1990). Hess et al. (1996) reported that supplementation of wheat bran rather than cracked corn did not seem to alleviate the reduction in forage intake or $\mathrm{OM}$ digestion. They suggested that although wheat bran has approximately $71 \%$ of the metabolizable energy content of corn, an amount of wheat bran less than that isocaloric to corn may provide similar production responses due to the reduction of negative associative effects on forage intake and digestibility. Therefore, when economically justified, wheat bran can be used in isocaloric quantities to corn for steers in the late fattening period. Narukawa et al. (2010) reported that palatability was decreased with increased catechins concentration in green tea. Accordingly, we thought that catechins could have an influence on feed palatability and consequently on intake and growth performance of steers. Furthermore, Silanikove et al. (1994) reported that animals fed tannin-rich diets had decreased feed intake. However, DMI was not different among the treatments in the present study. In addition, BW gain and ADG were not significantly different for catechins and CW compared with control. Therefore, a catechin supplement of $0.5 \%$ in the diets of the late fattening period did not adversely influence the growth performance of Hanwoo steers.

The effect of treatments on carcass characteristics is presented in Table 3. Treatment with catechins, wheat bran and $\mathrm{CW}$ did not affect carcass weight or loin-eye area. For back fat thickness, results show that wheat bran was the lowest of all treatments $(\mathrm{p}<0.05)$. Dressing percentage was higher for wheat bran than for other treatments $(p<0.05)$.
Marbling score, panel meat color and fat color, and texture were not different among the treatments. For meat maturity, wheat bran and CW were superior to control $(\mathrm{p}<0.05)$, and catechins tended to be better than control. Although supplementing steer diets with wheat bran and catechins improved the back fat thickness, dressing percentage, and maturity carcass characteristics, it had an no effect on yield and quality grade.

Table 4 shows the effect of treatments on the display life of meat represented by myoglobin, oxymyogolbin, metmyoglobin percentage and total myoglobin concentration in longissimus dorsi. Myoglobin percentage and total myoglobin concentration in the M. longissimus dorsi were not significantly different among the treatments, whereas oxymyoglobin percentage was the highest for CW. Compared with other treatments, the percentage of oxymyoglobin was the highest for $\mathrm{CW}$ during the entire meat display time from 1 to $24 \mathrm{~h}$. No other significant treatment effects on oxymyoglobin were noted. Oxymyoglobin is commonly known to be responsible for fresh meat color. After meat is cut, the color is a deep purplish red. As oxygen from the air comes into contact with the exposed meat surfaces, it is absorbed and binds to the iron in myoglobin. The surface of the meat blooms as myoglobin is oxygenated. This pigment, called oxymyoglobin, gives beef its bright cherry red color which consumers associate with freshness. In the present study, a higher oxymyoglobin percentage for $\mathrm{CW}$ would be associated with a more desirable bright reddish pink color or less color deterioration. Previous studies have reported that antioxidants prevent discoloration (Waylan et al., 2002; 
Table 4. Effect of experimental diets on the display time of M. longissimus dorsi represented by myoglobin, oxymyogolbin, and metmyoglobin percentage and total myoglobin concentration in Hanwoo steers

\begin{tabular}{|c|c|c|c|c|c|c|}
\hline \multirow{2}{*}{ Items } & \multirow{2}{*}{$\begin{array}{l}\text { Display } \\
\text { time (h) }\end{array}$} & \multicolumn{4}{|c|}{ Experimental supplements } & \multirow{2}{*}{ SEM $^{1}$} \\
\hline & & Control & Catechins & Wheat bran & $\mathrm{CW}$ & \\
\hline \multirow[t]{3}{*}{ Myoglobin (\%) } & 1 & 9.04 & 11.76 & 12.41 & 10.18 & 0.89 \\
\hline & 5 & 8.69 & 9.71 & 10.56 & 9.44 & 0.32 \\
\hline & 24 & 8.27 & 6.78 & 8.45 & 7.60 & 0.54 \\
\hline \multirow[t]{3}{*}{ Oxymyoglobin (\%) } & 1 & $78.35^{\mathrm{b}}$ & $74.20^{\mathrm{bc}}$ & $72.46^{\mathrm{c}}$ & $83.77^{\mathrm{a}}$ & 1.14 \\
\hline & 5 & $69.12^{\mathrm{b}}$ & $68.38^{\mathrm{b}}$ & $66.78^{\mathrm{b}}$ & $77.27^{\mathrm{a}}$ & 0.96 \\
\hline & 24 & $33.01^{\mathrm{b}}$ & $35.79^{\mathrm{b}}$ & $30.71^{\mathrm{b}}$ & $53.67^{\mathrm{a}}$ & 2.09 \\
\hline \multirow[t]{3}{*}{ Metmyoglobin (\%) } & 1 & 3.67 & 4.12 & 5.06 & 2.66 & 1.08 \\
\hline & 5 & $14.18^{\mathrm{a}}$ & $13.12^{\mathrm{a}}$ & $13.61^{\mathrm{a}}$ & $4.30^{\mathrm{b}}$ & 0.88 \\
\hline & 24 & $53.34^{\mathrm{a}}$ & $51.92^{\mathrm{a}}$ & $55.34^{\mathrm{a}}$ & $31.76^{\mathrm{b}}$ & 2.19 \\
\hline \multirow[t]{3}{*}{ Total myoglobin $(\mathrm{ml} / \mathrm{mg})$} & 1 & 1.04 & 1.03 & 1.02 & 1.13 & 0.02 \\
\hline & 5 & 1.10 & 1.07 & 1.09 & 1.21 & 0.02 \\
\hline & 24 & 1.35 & 1.43 & 1.43 & 1.47 & 0.03 \\
\hline \multirow[t]{3}{*}{ Total myoglobin (mg/g tissue) } & 1 & 5.22 & 5.17 & 5.08 & 5.64 & 0.11 \\
\hline & 5 & 5.48 & 5.34 & 5.43 & 6.03 & 0.12 \\
\hline & 24 & 6.75 & 7.16 & 7.15 & 7.37 & 0.17 \\
\hline
\end{tabular}

${ }^{1}$ SEM $=$ Standard error of the mean. ${ }^{\text {a,b,c }}$ Means with different superscripts within the same row are significantly different $(\mathrm{p}<0.05)$.

Zhong et al., 2009). Therefore, CW may prevent the discoloration of beef.

There were no significant differences among treatments on percentage of metmyoglobin at $1 \mathrm{~h}$ display time. Metmyoglobin percentages were lower for CW at 5 and 24 $\mathrm{h}$ compared with other treatments. Catechins and wheat bran were not significantly different compared with control. As display time passed, $\mathrm{CW}$ had a reduced rate of increase of metmyoglobin percentage that resulted in an increased display time in comparison with other treatments. As a result, metmyoglobin percentage was the lowest for $\mathrm{CW}$ at 5 and $24 \mathrm{~h}$ of display time. These results suggest that supplying $\mathrm{CW}$ as a dietary supplement in the late fattening period of Hanwoo steers has the potential to retard myoglobin oxidation in beef. At $24 \mathrm{~h}$ of displayed time, the percentage of metmyoglobin for $\mathrm{CW}$ was significantly lower than that of other treatments. Percentage of metmyoglobin was $31.76 \%$ for CW, compared with 53.34 , 51.92 , and $55.34 \%$ for control, catechins, and wheat bran treatments, respectively. Metmyoglobin, the oxidised form of the oxygen-carrying protein myoglobin, is the cause of the characteristic brown discoloration of meat. Visually detectable percentages and consumer rejection levels of metmyoglobin by both trained and consumer-type panels have been reported. Van der Oord and Wesdorp (1971) confirmed that the visually detectable level of metmyoglobin was at $50 \%$ of total myoglobin. Greene et al. (1971) reported that consumer rejection occurred at $40 \%$ metmyoglobin. According to our results, metmyoglobin percentage in the tissue of the steers receiving $\mathrm{CW}$ was lower than the above-reported results. Therefore, supplying $\mathrm{CW}$ as a dietary supplement may improve meat color because pigment stability in muscle is linked to myoglobin oxidation in meat. $\mathrm{CW}$ may provide protection against oxidation of myoglobin in our present study.

Treatment means for blood iron and hemoglobin, and tissue iron concentration are presented in Table 5. Blood iron and hemoglobin concentration were numerically lower for catechins than other treatments, but there were no significant differences among treatments. Total concentration of muscle iron was the lowest $(p<0.05)$ for CW.

Miltenburg et al. (1992) reported that blood hemoglobin concentrations were significantly associated with intramuscular iron levels in the veal carcass. Wensing et al. (1986) reported that iron supply management during the

Table 5. Effect of experimental diets on serum iron and hemoglobin concentration, and total muscle iron concentration in Hanwoo steers

\begin{tabular}{|c|c|c|c|c|c|}
\hline \multirow{2}{*}{ Items } & \multicolumn{4}{|c|}{ Experimental supplements } & \multirow{2}{*}{ SEM $^{1}$} \\
\hline & Control & Catechins & Wheat bran & $\mathrm{CW}$ & \\
\hline Blood iron $(\mathrm{mg} / \mathrm{L})$ & 2.11 & 1.99 & 2.20 & 2.20 & 0.33 \\
\hline Blood hemoglobin $(\mathrm{g} / \mathrm{dl})$ & 15.86 & 14.64 & 15.10 & 15.11 & 0.68 \\
\hline Total muscle iron $(\mathrm{mg} / \mathrm{kg})$ & $27.28^{\mathrm{ab}}$ & $26.80^{\mathrm{ab}}$ & $29.76^{\mathrm{a}}$ & $22.32^{\mathrm{b}}$ & 0.90 \\
\hline
\end{tabular}

${ }^{1} \mathrm{SEM}=$ Standard error of the mean. ${ }^{\mathrm{a}, \mathrm{b}}$ Means with different superscripts within the same row are significantly different $(\mathrm{p}<0.05)$. 
fattening period to control veal color is more reliant on blood hemoglobin concentration than on plasma iron concentration. Although blood hemoglobin concentration was numerically lower for catechins, wheat bran and CW than that of steers fed a basal diet (control), there was no correlation between blood hemoglobin or plasma iron concentration and total muscle iron concentration in the present study. The lack of correlation may be due to steer age, since meat color is commonly known to be related to age. Pigment content in the muscle increases from birth to 16 months of age (Boccard et al., 1979). Brightness of meat is increased up to 16 months of age and chroma of meat is increased up to 18 months of age, and then both remain constant. As a result, meat color is generally fixed by 18 months of age in the Hanwoo (Ha et al., 2005) because meat color is depended on total pigment content, brightness, and chroma of meat. We conducted this study using steers at 20 months of age. Therefore, further study may be needed using animals under 18 months of age to determine whether muscle iron concentration has a correlation with blood hemoglobin or plasma iron concentration.

Agboola et al. (1988) suggested that phosphate radicals will inhibit myoglobin synthesis by chelation of iron. Phosphate inhibits the absorption of iron in the digestive tract, therefore, phosphate may be used to manipulate the iron and consequently the myoglobin concentration in the muscular tissue. Zembayashi et al. (1999) reported that green tea decreased the absorption of iron in the muscle. Therefore, wheat bran and catechins as a source of phosphate and a source of phenolic antioxidant may lead to improved meat color. However, catechins and wheat bran treatments individually did not significantly prevent the accumulation of iron in the muscle. It is unclear why supplying catechins and wheat bran alone did not influence the meat color. Catechins and wheat bran are not commonly fed to steers in Korea under normal production conditions because information is limited on the effects of dietary supplementation with these ingredients in Hanwoo steers. It is possible that catechins and wheat bran alone may lead to improved meat color if the inclusion rate was higher than in the present study. However, this hypothesis requires further investigation. On the other hand, $\mathrm{CW}$ was effective in preventing an accumulation of total muscle iron. Zembayashi et al. (1999) conducted a study that confirmed the effects of green tea and wheat bran on meat color using several breeds raised either in Japan or the USA. They obtained samples of M. longissimus thoracis, semimembranosus and gluteous medius, and compared the effects of green tea and wheat bran among different muscles. The study confirmed that the iron content of the $M$. semimembranosus from the tea-fed cattle was lower than in M. semimembranosus from a basal diet. The iron content of the other muscles was not affected by dietary bran or tea.
The M. longissimus thoracis contained less iron than the M. gluteous medius. The M. semimembranosus was intermediate in iron content to the other two muscles. Consequently, iron content may be affected more by muscle type than by diet type. In addition, they indicated that the effect of dietary bran on muscle iron content was greater in Japanese Black cattle than in either the Japanese Brownx Japanese Black/Holstein or the Charolais $\times$ Japanese Black/Holstein cattle. Therefore, further detailed studies may be needed to verify whether iron content will be affected by different muscle types in Hanwoo steers, and which type of muscle will be influenced by those treatments in Hanwoo steers.

\section{CONCLUSION}

$\mathrm{CW}$, a mixture of catechins and wheat bran, improved meat color by providing protection against oxidation of myoglobin in late fattening period of Hanwoo steers. Treatment with CW in Hanwoo steers did not improve the panel meat color, but may prevent the discoloration of beef in display cases at market. Furthermore, it is generally accepted that meat color is fixed before 18 months of age in Hanwoo steers. However, our present study suggests that meat color can be altered by a nutritional manipulation in the late fattening period of Hanwoo steers.

\section{REFERENCES}

Agboola, H. A., V. R. Cahill, H. R. Conrad, H. W. Ockerman, N. A. Parrett and R. F. Plimpton. 1988. The effects of a high monosodium phosphate and alpha-tocopherol supplemented milk replacer diet on veal muscle color and composition. J. Anim. Sci. 66:1676-1685.

AOAC. 1990. Official methods of analysis. 15th Ed. Association of official analytical chemists. Washington, DC, USA.

Boccard, R. L., R. T. Naude, D. E. Cronje, M. C. Smit, H. J. Venter, and E. J. Rossouw. 1979. The influence of age, sex and breed of cattle on their muscle characteristics. Meat. Sci. 3:261-280.

Bray, R. W., E. H. Rupnow, F. M. Hanning, N. N. Allen and R. P. Niedermie. 1959. Effect of feeding methods on veal production and carcass quality. 11. Carcass gades, liver, hide, specific gravity, yield and chemical analysis of muxle. J. Anim. Sci. 18:732.

Carpenter, C. E., D. P. Cornforth and D. Whittler. 2001. Consumer preferences for beef color and packaging did not affect eating satisfaction. Meat. Sci. 57:359-363.

Cassens, R. G., C. Faustman and F. Jimenez-Colmenero. 1988. Modern developments in research on colour of meat. Pages 211 in Trends in Modern Meat Technology 2 (Ed. B. Krut, P. VanRoon, and J. Houben). Pudoc, Wageningen, the Netherlands.

Disler, P. B., S. R. Lynch, R. W. Charlton, J. D. Torrance, T. H. Bothwell, R. B. Walker and F. Mayet. 1975. The effect of tea on iron absorption. Gut 16:193-200.

Fleming, H. P., T. N. Blumer and H. B. Craig. 1960. Quantitative 
estimations of myoglobin and hemoglobin in beef muscle extracts. J. Anim. Sci. 19:1164-1171.

Goto, T., Y. Yoshida, M. Kiso and H. Nagashima. 1996. Simultaneous analysis of individual catechins and caffeine in green tea. J. Chromatogr. A 749:295-299.

Greene, B., I. M. Hsin and M. Zipser. 1971. Retardation of oxidative color changes in raw ground beef. J. Food Sci. 36:940-942.

Ha, J. K., S. S. Lee, Y. S. Moon and C. H. Kim. 2005. Ruminant nutrition and physiology. SNU Press, Korea. Pages 464-465.

Hess, B. W., L. J. Krysl, M. B. Judkins, D. W. Holcombe, J. D. Hess, D. R. Hanks and S. A. Huber. 1996. Supplemental cracked corn or wheat bran for steers grazing endophyte-free fescue pasture: effects on live weight gain, nutrient quality, forage intake, particulate and fluid kinetics, ruminal fermentation, and digestion. J. Anim. Sci. 74:1116-1125.

Martin, S. K. and C. A. Hibberd. 1990. Intake and digestibility of low-quality native grass hay by beef-cows supplemented with graded-levels of soybean hulls. J. Anim. Sci. 68:4319-4325.

Miltenburg, G. A., T. Wensing, F. J. Smulders and H. J. Breukink. 1992. Relationship between blood hemoglobin, plasma and tissue iron, muscle heme pigment, and carcass color of veal. J. Anim. Sci. 70:2766-2772.

Monsen, E. R. 1988. Iron nutrition and absorption: dietary factors which impact iron bioavailability. J. Am. Diet Assoc. 88:786790 .

Narukawa, M., H. Kimata, C. Noga and T. Watanabe. 2010. Taste characterisation of green tea catechins. Int. J. Food Sci. Technol. 45:1579-1585.

NRC. 2000. Nutrient requirements of beef cattle. 7th rev. ed. Natl. Acad. Press, Washington, DC, USA.
Onyeneho, S. N. and N. S. Hettiarachchy. 1992. Antioxidant activity of durum-wheat bran. J. Agric. Food Chem. 40:14961500.

Rhee, K. S. and Y. A. Ziprin. 1987. Modification of the schricker nonheme iron method to minimize pigment effects for red meats. J. Food Sci. 52:1174-1176.

Silanikove, N., Z. Nitsan and A. Pfevolotsky. 1994. Effect of a daily supplementation of polyethylene glycol on intake and digestion of tannin-containing leaves (Cernatonia siliqua) by sheep. J. Agric. Food Chem. 42:2844-2847.

Van der Oord, A. and J. Wesdorp. 1971. Analysis of pigments in intact beef samples. J. Food Technol. 6:1-13.

Van Soest, P. J., J. D. Robertson and B. A. Lewis. 1991. Methods for dietary fiber, neutral detergent fiber, and nonstarch polysaccharides in relation to animal nutrition. J. Dairy Sci. 74:3583-3597.

Waylan, A. T., P. R. O'Quinn, J. A. Unruh, J. L. Nelssen, R. D. Goodband, J. C. Woodworth, M. D. Tokach and S. I. Koo. 2002. Effects of modified tall oil and vitamin E on growth performance, carcass characteristics, and meat quality of growing-finishing pigs. J. Anim. Sci. 80:1575-1585.

Wensing, T., A. I. Abdelrahim and A. J. H. Schotman. 1986. Some aspects of extra iron supply in veal calf fattening. Vet. Res. Commun. 10:283-296.

Zembayashi, M., D. K. Lunt and S. B. Smith. 1999. Dietary tea reduces the iron content of beef. Meat Sci. 53:221-226.

Zhong, R. Z., C. Y. Tan, X. F. Han, S. X. Tang, Z. L. Tan and B. Zeng. 2009. Effect of dietary tea catechins supplementation in goats on the quality of meat kept under refrigeration. Small Rumin. Res. 87:122-125. 